has proved his assertion, by the result of a large experience, that such operations are successful by chance rather than upon principle; and if there is one region of the body in which an operation of this kind is more likely to be unsuccessful than another, it is, I believe, in the axilla, for the reasons above stated.

Gower-street, Bedford-square, 1848.

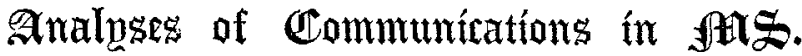
RECEIVED FOR PUBLICATION IN THE LANCET.

\section{An Account of Two Cases of Placenta Provia in which the Established Treatment by Turning was Employed Successfully.}

By Elmes Yelverton Steele, Esq., M.R.C.S.E. \& L.S.A., Abergavenny.

CASE 1.-On May 30th, 1847, I was called to attend a woman, aged forty years, arrived at about the full period of her seventh pregnancy, and who had been losing blood almost incessantly for more than ten days previously. Medical aid had not been sought for before, owing to straitened circumstances. During the whole of the preceding night, however, and throughout that day, the hæmorrhage had been gradually increasing, till it had attained to a fearful extent; and on arriving at the cottage, I found the unfortunate patient lying on the stone floor, where, at her own request, she had been stretched for some time, weltering in her blood, and with no other covering than her bedgown. Her skin was cold, clammy, and perfectly blanched; lips quite colourless; eyes fixed; jaw relaxed; pulse imperceptible, and she had every appearance of being in articulo mortis. I caused her to be carefully lifted on to the edge of the bed resting on her left side, and passed a bandage around the abdomen. Up to that moment, although the full period had been attained, she had shown no evidence of pain, nor any other indication of approaching labour than the hæmorrhage. On examining, I found the os nearly as high as the level of the brim of the pelvis, and dilated to the diameter of about two inches, its lips being thin and flaccid. A loose portion of placenta was bagging through the orifice, occupying the whole circumference, but traceable within the uterus anteriorly to its continuation with the unruptured membranes, and posteriorly to its adhering portion, which commenced about three inches above the free edge of the posterior lip of the uterus. From that point blood could be felt oozing away. I ascertained through the membranes that the head was presenting, and as no contraction was produced by pressure and friction over the abdomen, I felt that not a moment should be lost in attempting to deliver by turning. I ordered a full dose of ergot in some brandy-and-water, and whilst the attendants with difficulty forced it down her throat, I ruptured the membranes, and readily passed my hand around the head fairly into the cavity of the uterus. In doing this I met with tha funis, and found that it had ceased to pulsate. Reaching the feet, I brought them down without any difficulty; and so soon as the head became engaged in the cavity of the pelvis, it pressed upon the placenta, and produced immediate arrest of the hæmorrhage. Expulsive pains simultaneously came on, and in the course of a few minutes delivery was accomplished by the natural efforts, excited in a slight degree by gentle traction. The bandage was immediately tightened around the abdomen, and after separating the child, which had evidently been dead for a considerable time, and seemed perfectly drained of blood, I re-introduced my hand into the vagina, to ascertain the progress of the placenta, which the uterus contracted sufficiently to expel in abont ten minutes, without any return of flooding. I remained with my patient for about two hours after her delivery, during which time she rallied gradually under the influence of stimulants. At about the sixth day a troublesome diarrhœe ensued, which subsided under the influence of opiates and absorbent remedies, followed by castor oil.

CASE 2.- On July the 22nd I was requested by Dr. Samuel Steele to accompany him immediately to a case of labour which he was attending in this town. The account he gave me on our way to the house was to this effect:-Mrs. C- - , aged twenty-four years, had arrived at about the full period of her first pregnancy, and had sent for him a week previously, when he found her suffering from uterine hæmorrhage, attended by slight, and as he thought, spurious labour pains. The os uteri on examination was not found sufficiently dilated to admit the tip of the index finger. Under the administration of an opiate and some castor oil the attack passed off, but was followed by a return at intervals during the week, the os uteri at each examination being proved to be very slowly dilating. On the day alluded to, he was sent for, in consequence of a violent and sudden hrmorrtage, and on arriving at the house he found blood gushing from the uterus at a fearful rate, and the patient apparently sinking. Seriously alarmed for her safety, he sought my assistance. Her pulse was thread-like; her skin cold and blanched; countenance extremely anxious, jactitation and yawning uncontrollable. On examination I found blood freely gushing from the vagina; the os uteri was high up in the pelvis, and dilated to the extent of a crown-piece, but otherwise tense, and filled up with a protruding mass of placenta. The liquor amnii had been discharged, and the uterus was contracting firmly. On passing my finger up between the placenta and the anterior lip of the uterus, I could distinguish that the head was presenting. I intended to leave to Dr. Steele the active duty in the case; but on looking at that moment to the patient's countenance, I saw what appeared to me, as to all present, so marked a sign of threatening dissolution, that I felt there was no time to be lost if her life were to be saved, and, with Dr. Steele's concurrence, I decided upon delivering at once. I found that as my hand passed through the os it controlled the hæmorrhage by acting as a compress on the placenta; and after much difficulty, owing to the now vigorous contractions of the uterus, and the absence of the liquor amnii, I ultimately succeeded in bringing down first one and then the other foot. Delivery was not completely effected for a considerable time, but as no hæmorrhage had returned, and the rigidity of the soft parts required careful relaxation, I did not attempt greatly to accelerate the process, more especially as the funis was not pulsating, and I had given up for some time all hope of saving the life of the child, which was expelled dead after about an hour from the commencement of my efforts. The placenta followed in about twenty minutes. The patient recovered favourably the third day, with the exception of a slight threatening of peritonæal fever.

The above two cases, though very similar in point of urgency and in their favourable termination, present several circumstances of totally opposite bearing. In the first, the patient was middle-aged, multipare, the os was dilated and yielding, the uterus soft and uncontractile, the membranes were entire, and the soft parts well relaxed. In the second, the patient was comparatively young, primipare, the os but slightly dilated and rigid, the uterus firmly contracted, the liquor amnii discharged, and the soft parts extremely tense. But in both the hæmorrhage ceased on compression of the placenta-in one, by the pressure of the head of the foetus, in the other, by that of the hand and arm of the operator. In both, version was successfully performed, and was followed by results as satisfactory to the mother as could have been hoped for under any mode of treatment; and as the child had in either case, - at least, as I firmly believe,--already fallen a sacrifice, no advantage could have been secured by any other means adopted.

\section{On the Inhalation of Ether in Midwifery Practice.}

By S. Gower, Esq., M.R.C.S.E. \&c., Hampstead, LATE MEDICAL OFFICER TO THE HOLME AND WOOLDALE DISTRICTS OF THE HUDDERSFIELD UNION.

Mr. Gower commences his remarks by throwing out the hint, that the inhalation of sulphuric ether might be found to attemper the pain, and diminish the frequency of attacks of tic-douloureux; such a result has, he says, occurred from the use of tobacco and other kindred narcotic remedies, in several instances which have come under his treatment. With respect to the inhalation of ether in midwifery practice he states:-

"The charges brought against its use seem to be-first, that it retards delivery, by checking the action of the motory nerves, and suspending expulsive efforts; secondly, that it endangers the brain, and is calculated to produce convulsions. That in practice it does not in the least degree check expulsive efforts, I am quite sure; that it tends to produce convulsions, I do not at all believe; always premising that it be used at the proper crisis, and that its effects be well watched. I do not characterize ether as a certain remedy for puerperal convulsions, but it is a remedy for the pain and the constitutional irritation set up by long and severe pain in cases of dystocia diutina, when there is pressure from impaction, or slowness of progress otherwise."

He accordingly cites the following case in point:-

"The patient was of a temperament impressible in the extreme; the spine not distorted, but the pelvis small; hence, 
during the latter three or four months of gestation, owing to the smallness of the pelvic basin, there was a protuberance like a sugar loaf, and knowing nurses prognosticated twins. Her age was thirty-nine; she had borne five living children and three seven-months still-born children, having had several precursory or intermediate miscarriages, accompanied, some of them, with frightful floodings, by which she was quite blanched, and at the time, her life often imperilled, and her constitution much undermined. From two miscarriages of this kind she had pretty well recovered; these were immediately antecedent to the accouchement of which I am about to speak. I had been her sole attendant at the birth of all her children; I can therefore speak with confidence of the character of her accouchements. As might have been expected, they were cases of dystocia dintina always. The head of the child was always long in taking the last oblique turn towards and through the os externum, the pains preliminary to this stage being many and lengthened. The os internum would be dilated to half the circumference of the child's head; the head would be within two fingers'-breadths of the os externum; it would proceed to press upon the distended perinæum; and from an hour and a half to three hours, after the degree of dilatation mentioned, would be occupied in efforts at expulsion. The agony in her previous confinement, at this crisis, was such as to retard labour, by inducing fainting fits and threatening convulsions; the perinæum at last gave way so slowly as to require support continually for a long period, and to render it not desirable that the expulsive efforts should be stronger, lest laceration should ensue. In short, the latter pains were proved, by her frequent faintings, to be beyond what Nature could endure, without the relief of temporary insensibility. Upon this present occasion I resolved-having her own free consent-to employ the inhalation of ether when the case seemed to me most to require itthat is, when the dilatation of the os internum should be complete. Labour-pains had commenced about four in the morning, and had continued all day. At about half-past ten at night, the period above described having arrived, and the agony, as usual, become intolerable, I soaked a sponge with ether, and applied it. Before many inhalations, she said she was quite free from all pain. A little loquacity ensued, and expulsive efforts then took place, without having been at all abated in force or frequency by the inhalation. There was not impaction; there was, what is always in a slow labour preferable, a considerable recession of the child's head after each pain; it, however, upon the whole, continued upon the advance. The patient, as the sponge parted with the ether, called eagerly for more, expressing most gratefully the immunity from pain it had given her. I took this of itself as a sufficient proof of its not having been earried too far, and I twice gave her also fifteen grains of ergot in gruel, to expedite delivery-an agent which, had it not been for such freedom from pain, I should not have ventured upon administering."

Mr. Gower supposes that from an ounce and a half to two ounces of ether might have been inhaled in this case, though a much larger quantity was placed on the sponge. "In fine, (he says, the child was born comparatively without pain, and the expressions of the patient were fervent and unbounded.

"Between three and four weeks having elapsed, both mother and child were doing well in all respects, without having had one untoward symptom or a menace of any. The child was larger than most of the patient's former children; and with the aid of the ergot of rye, (with the action of which the ether did not at all interfere, it was born sooner than had been commonly the case, whether reckoning the whole period of labour, or that period of it sequent upon the complete dilatation of the os tincre."

Mr. Gower calls to mind " multitudes of cases" happening in his thirty years obstetric practice, in which the employment of ether might have spared an infinity of needless suffering; and, in reference to the marvellous influence of anæsthetic agents, he records his opinion, "that it would be difficult to name any one discovery in medicine having an equal value."

\section{On the plea of Insanity in supposed criminal cases.}

By Fredertok Duesbury, M.D., Clapton.

On the above subject, especially in reference to the boy Allnutt's case, Dr. Duesbury first directs attention to articles in the Britannic Journal of Dec. 18th; in The Lanoen of Jan. 8th; two papers in the Domestic Lawyer of Jan. 8th-one exhibiting the views of Chief Baron Pollock, the other being a reply to the comments in the Timos of Jan. 24th; letters in the Medical Gazette of Jan. 14th, \&c. Quotations are made from letters by Dr. Conolly and Mr. George Combe to the author, coinciding with his sentiments respecting the particular case considered. Dr. Duesbury then remarks:-

"It may be satisfactory to learn that it was decided to send Allnut to Parkhurst, in the Isle of Wight, where it is to be presumed his case will be properly watched and treated, and with a reasonable prospect of success; looking to his age, the recent improvement of his health and remission of his symptoms, the locality, so well suited to his scrofulous complaints, and the important fact that the opportunities and exciting causes will be there avoided, and some suitable employment provided.

"The first and obvious inference to be drawn from the facts of the case is this-that if we are to suppose all these acts, so totally motiveless, indiscriminate, and unnatural, to have arisen from mere depravity and crime, and not from unsoundness of mind, we must at the same time suppose such a monster of wickedness as I believe the world never saw, and, I should hope, will not be likely to see; and of which the records of crime, wide and large as they are, do not show any similar instances, at his age, and under the circumstances by which he was surrounded. But I apprehend-1st, that the boy inherited such predispositions as were likely to lead to insanity; 2ndly, that the injuries he received about the head, the eruptive, scrofulous, and other diseases under which he suffered, were amply sufficient to develop unsoundness of mind in one so far predisposed; 3rdly, that this unsoundness first exhibited itself in a deranged state of his moral feelings, which advanced so far ultimately as to render him totally insensible to moral and religious impressions and obligationsthe mere intellect, which remained unaffected, being too slow and inefficient in its operations to counteract or repair the loss. This is like the ship that has lost her rudder, and is left merely to her chart and compass to avoid a shipwreck.

"We have a further stage of disease to consider, when the lower or instinctive feelings or propensities, and particularly the destructive ones, became affected and were brought under excitement, and this, too, at a time when the above controlling moral power was lost; what had we, therefore, to expect from such a deplorable state of mind, when left to act without restraint, but the painful results which followed? It is similar to the above ship, when under the additional impulse of the storm, (representing the passions, ) which has driven her on to shipwreck, (or the destructive acts of insanity,) whilst her rudder (corresponding to the moral feelings or conscience) was damaged or lost; - her chart and compass (which represent the intellect) might perhaps tell where she had drifted and where she had struck, but could not control her course or avert her doom. And such, I apprehend, has been and will be the fate of many others, until we are prepared to admit that the moral feelings, the propensities, and the intellect, are separate and distinct departments of the human mind; that they may be separately, successively, or simultaneously affected by insanity or disease in different cases; and that where the intellect alone remains intact, we cannot rely upon it, either for the safety of the individual or of those around him. This shows the great importance of our being able to recognise early cases when self-control is lost, and of having them placed under proper restraint, so as to avoid those too often appalling exhibitions and results, which, as being the consequences of disease, are certain to be the more monstrous and unnatural; and that have also been found to produce so injurious an effect on the public feelings, and to determine or excite many wavering or predisposed minds into similar acts.

"The boy Allnutt is small in stature for his age of twelve years; he is very short-necked, and with a head disproportionately large, chiefly from the great development of the frontal region; the head being more remarkable for its length than for either its breadth or height. I always found in him, during the last spring, a languid circulation and coldness of the extremities, with increased heat about the sides and back of his head, complaint of frequent headaches, particularly after reading or any mental exertion, with giddiness, confused feeling, and other indications in lis complexion, eye, \&c., of some vascular congestion about the head. His serious, vacant, and abstracted expression and manner particularly struck me at first, (and I believe Dr. Conolly also,) and led me to observe, after my first interview with the boy in March last, that I thought there was a great peculiarity about him, using the expression, ' a twist about his head,' and that ' $I$ might as well appeal to the house-side as attempt to remove any notion, however absurd, he had got in his head." He had strong marks of scrofula about him, with considerable 